\title{
3. Надь
}

\section{ВАСЮГАН НА РУБЕЖЕ СТОЛЕТИЙ: ХАНТЫ ИЛИ ОСТЯКИ?}

\begin{abstract}
На примере васюганских хантов показывается, как этническая группа может исчезнуть, а затем снова появиться в локальных дискурсах, т.е. как аборигенное население может затеряться между социально-бытовым и этническим дискурсами. На протяжении прошлого века васюганские ханты сначала маргинализировались, а затем из бытовой группы без какого-либо политического, культурного и хозяйственного веса они превратились в этническую группу, обладающую весьма серьезным потенциалом. Процесс развивается в двух неразрывно связанных друг с другом направлениях - в направлении патримонизации и травматизации.

Ключевые слова: ханты; культурная травма; патримонизация; культурная память.
\end{abstract}

В своей статье я хотел бы рассказать о репрезентации в публичном дискурсе васюганских хантов, проживающих на территории Томской области, что является главной темой моих последних исследований. Прежде всего обратим внимание на вопросы, возникающие в связи с употреблением слов «ханты» и «остяки».

Люди, которых исследователи обычно выделяют как группу «васюганских хантов», сами никогда не называют себя «хантами». Говоря на русском языке (а васюганский диалект сейчас уже, в сущности, никто не употребляет в повседневной коммуникативной практике), они совершенно естественно называют себя «остяками»; и точно так же называет их и окружающее нехантыйское население. Таким способом местные жители терминологически отделяют себя от хантов, проживающих на территории Ханты-Мансийского автономного округа, которых они называют либо просто «хантами», либо «ханты-манси». В то же время «остяками» они называют также и селькупов, проживающих на территории Томской области, которые, по их словам, «такие же остяки, как и мы, только говорят на другом языке». Следовательно, нельзя однозначно утверждать, что используемые наукой этнические категории в полной мере применимы к обозначаемым этими категориями группам и что местная категоризация во всем соответствует научной [1]. Более того, сказанное выше ставит под сомнение и то, что местное население использует те же классификационные единицы, что и научная терминология, поскольку, как видим, языковые различия с их точки зрения индифферентны, тогда как определяющую роль играют такие факторы, как образ жизни, общность территории проживания или сознание того, что они являются представителями местного коренного населения. Ввиду этого в дальнейшем я намеренно буду употреблять термин «остяки» по отношению к коренному меньшинству территории Васюганья.

Демографическая ситуация Томской области обусловлена прежде всего систематическими выселениями 1930-х и 1940-х гг., когда на территории проживания «остяков» были депортированы огромные массы переселенцев, преимущественно русских, немцев и жителей стран Прибалтики. В 1960-х гг. произошел резкий всплеск трудовой миграции, вызванный бурным ростом нефтяной и газовой промышленности, что лишь ускорило тот процесс, в результате которого местные «остяки» практически растворились в пришлом, «не остяцком» населении. В Новом Васюгане, главном объекте моих исследований, основанном в 1933 г., на 2014 г. численность населения составляла 2579 человек, из них «остяков» около 100 человек, что едва достигает 4\% от общего числа населения ${ }^{1}$. По данным переписи населения 2010 г., на территории Каргасокского района, к которому относится и Новый Васюган, численность хантов составляет 192 человека, т.е. $0,88 \%$, тогда как на всей территории Томской области с населением свыше 1 млн человек их число не достигает 720 человек, что составляет всего $0,07 \%$ от общей численности населения [2].

На официальном сайте Нового Васюгана ${ }^{2}$ нигде не упоминается тот факт, что в селе живут «остяки». В «паспорте поселения», размещенном на портале, отсуствуют данные относительно национальности жителей. Ни в общих сведениях о Новом Васюгане, ни в краткой исторической справке не говорится о том, что село построено на территории, где раньше жили «остяки». Такое же «умолчание» обнаруживается и при рассмотрении гербов, официальных плакатов, изданий Нового Васюгана. То есть официальный облик села не учитывает факта существования «остяков».

«Невидимость» аборигенного населения наблюдается и в творчестве местных писателей и поэтов, таких как Василий Борзецов [3] или Сергей Дорофеев [4], а также в произведениях так называемой нефтяной романтики, например Петра Шаповалова [5] или барда Юрия Зонова. Несмотря на очевидную привязанность авторов к своему краю, в текстах эта территория изображается как враждебная, безлюдная, непроходимая глухомань, которую пришлось покорить, отвоевать у тайги, чтобы создать необходимые условия для жизни русского человека. То есть нигде не говорится о том, что этот край прежде был населенным: на частном уровне глухая, безлюдная тайга была преобразована в благоприятную для человеческой жизни территорию, а 
на политическом уровне бесплодная с хозяйственной точки зрения тайга - в крупный народнохозяйственный ресурс.

Лес воспринимается как противоположность цивилизации. С этой точки зрения присутствие «остяков», по сути дела, не играет существенной роли, так как в противоположность русскому человеку они не цивилизовали, не гуманизировали тайгу, как раз напротив, тайга «натурализовала» их. До выселений «остяки» считались скорее частью природы, чем членами современного общества. Такие особенности, как образ жизни, близкий к природе, отсутствие производства, «первобытность» (в советском понимании) представляли их как неотъемлемую часть леса, чуждую цивилизации. Таким образом, с точки зрения «безлюдности», «необитаемости» территории присутствие «остяков» не имеет значения.

«Остяки» занимают весьма незначительное место в публичных сферах области и района. Как в институциональной политике памяти, так и в популярной памяти (popular memory), которые ни в коем случае не следует смешивать с форумами научной историографии, в качестве предпосылки «подлинной» русской истории выступают почти исключительно археологические культуры. То есть носителями «дорусской» истории являются не местные «коренные» народы, а археологические культуры.

Одной из причин невидимости «остяков» является представление, сформировавшееся в локальном обществе по отношению к ним. В общественном мнении села, района и области «остяки», в сущности, выступают в качестве не этнической, а социально-бытовой группы, которая противопоставляется так называемому русскому образу жизни.

Это противопоставление имеет нейтральные оценочные компоненты, например представление о тесной связи «остяков» с лесом, тайгой. Образ жизни «остяков» основан преимущественно на рыболовстве и охотничьем промысле и, безусловно, тесно связан с таёжной жизнью. Это суждение остается в силе вопреки тому, что жизненный уклад «остяков» на практике почти не отличается от русских, ведущих лесной образ жизни. Можно сказать, что тайга и лес занимают весьма важное место в самооопределении обеих групп, разница в том, что «остяки» практически отождествляются с тайгой, считаются ее органичной частью, тогда как «не остяки» легко отделимы от леса, они «чужаки», только приходящие в лес, но не живущие в нем. Между лесом и «остяцким» обществом существует некая метафорическая связь: настоящий «остяк» тот, кто живет в лесу, жить по-настоящему значит жить в лесу, промышляя охотой и рыбной ловлей. В отличие от этого, с точки зрения русских, лес воспринимается как непредсказуемая, враждебная среда. Для «остяков» лес является неотъемлемой частью жизни, тогда как для русских это либо «зона отдыха», предоставляющая различные виды развлечений типа охоты на уток или пик- ника с шашлыком, либо способ добычи средств к жизни, основанный на принципе строгого хозяйственного расчета, который поддерживается до тех пор, пока не теряет свою рентабельность [6].

Более значимыми являются, однако, отрицательные коннотации, связанные с «остяками» как социальнобытовой группой: в восприятии местного населения «остяки» выступают преимущественно как культура бедности, как маргинальная культура. Это представление усиливается также тем, что прежние хантыйские поселения, которые на сегодняшний день уже почти полностью опустели, нередко становятся приютом опустившихся или разыскиваемых полицией людей, по тем или иным причинам вынужденных покинуть Новый Васюган. «Остяцкие поселения» со временем стали упоминаться как «поселения уголовников и алкоголиков», что также укрепило представление об «остяках» как «уголовниках и алкоголиках».

После всего вышесказанного необходимо снова обратиться к вопросу о различиях в употреблении слов «остяк» и «хант». Как мы видели, в местном русском словоупотреблении термин «остяк» отражает скорее бытовую, чем этническую категорию, тогда как слово «хант», напротив, больше связано с понятием этничности. Тем не менее такое разделение не совсем однозначно. Слово «остяк» используется исключительно в обиходной речи и никогда не употребляется в рамках политического дискурса ни в социальных вопросах, ни в вопросах культуры. Термин «хант», напротив, выступает в качестве этнической категории как в общероссийских статистиках, так и в законодательных текстах. Так называемые коренные этносы, к которым относятся «ханты» и «селькупы», обладают особым правовым статусом, обеспечивающим различные льготы. В то же время, в отличие от общепринятого словоупотребления, люди, называющие себя «остяками», воспринимают это понятие однозначно как этническую категорию, отличающую их не только от большинства общества, но и от хантов, проживающих на территории XMAO.

Отношение со стороны общества к «остякам» как маргинальной культуре бедности исключает возможность включения их судьбы и проблем в этнический дискурс, что могло бы обеспечить им доступ к политическим, экономическим и культурным ресурсам. В сложившихся обстоятельствах единственную возможность выхода на публичную арену этнические предприниматели видят в приобщении «остяков» к городскому понятию экзотичности, что означает показать себя таким образом, чтобы население обратило на них внимание и стало относиться к ним с любопытством и симпатией. Местные меньшинства, однако, должны приложить усилия, чтобы соответствовать понятию экзотичности, так как это качество, как правило, с ними не ассоциируется. Дело в том, что с начала XX в. культура «остяков» мало чем отличается от культуры «русских», следовательно они и тогда уже не соответствовали критерию экзотич- 
ности. Прототип «сибирства» и «аборигенности» воплощается здесь, прежде всего, в группе эвенков, что ярко отражается как в популярной культуре, так и в местной художественной литературе, например в произведениях Решетко [7] и Шелудякова [8].

Тем не менее на территории области все же известны «ханты», отвечающие требованию экзотичности. Эти «ханты», однако, идентифицируются здесь не с местными «остяками», а с коренным населением Ханты-Мансийского автономного округа. Так, например, в музее г. Стрежевой ${ }^{3}$ в одном из выставочных залов помещена отдельная экспозиция, посвященная «хантам», однако материал выставки собран не на территории соседнего Васюганья или Александровского района, а в Нижневартовском районе, также расположенном пососедству. Образ жизни коренного меньшинства родной области, как видно, недостаточно архаичен, экзотичен, выразителен для того, чтобы быть представленным в экспозиции.

По этой причине основное стремление объединений национальных меньшинств области должно быть направлено на то, чтобы при помощи сценической культуры, предметов народного творчества включить местные национальные меньшинства в дискурс об экзотичности и сделать их видимыми, предлагая таким образом новую интерпретацию вместо прежнего представления о люмпенизированной культуре. Этноэстрадная культура пользуется большим спросом на рынке, на основе этого можно организовать проекты, получать гранты. Другим эффективным способом изменения этнического дискурса является этнотуризм, представляющий местное коренное население опятьтаки как лесную, природную культуру, но на этот раз с использованием этнических категорий [9]. В этом контексте коренные жители представлены как люди, которые живут в гармонии с природой, которые могут служить примером для современной экологической мысли и помимо этого предоставляют посетителям возможность для отдыха и приключений.

Несмотря на все усилия этнических предпринимателей, в памяти области этнический дискурс не является определяющим. Это обстоятельство находится в соответствии с демографическими показателями. Согласно данным переписи населения 2010 г., 92,05\% населения области назвали себя русскими по национальности [2]. В этой этнически однородной среде в силу раздробленности и низкой численности этнических меньшинств их политический потенциал весьма незначителен, в политическом дискурсе о памяти ключевую роль играют не этнические вопросы, а исторические травмы.

Наиболее глубокой исторической травмой, занимающей основное место в политике идентичности Томской области как отдельной единицы, является период сталинских репрессий. Точное количество депортированных установить невозможно, но, по некоторым оценкам, доля репрессированных и их потомков на се- годняшний день превышает 70\% общей численности населения области [10-12]. Вследствие этого современное самосознание области и района формируется на основе сталинских репрессий. Ужасы депортации, о которых на протяжении многих десятилетий нельзя было говорить, в настоящее время играют особую роль в конструировании местной идентичности; это действительно драматическое событие претворилось в культурную травму, как понимает этот термин Дж. Александер [13]. Согласно сформировавшемуся в последнее время «господствующему нарративу» (master narrative), переселенцев в нечеловеческих условиях вывозили на территорию Нарымского края, оставляли на произвол судьбы, например на берегу Васюгана, где им приходилось без орудий и средств к существованию отвоевывать у враждебной природы, у тайги, необходимое жизненное пространство. Таким образом, на этой земле переселенцы были пионерами, которые помимо воли принесли культуру в этот безлюдный и пустынный край, ценой многих страданий покорили эту территорию и пожертвовали жизнью своих родных ради ее заселения. Страдание становится метафорой покорения, освоения края; страдание легитимизирует право на владение этой землей. В истории страданий переселенцев нет места коренным жителям. Повидимому, будь аборигенное население включено в нарратив памяти, переселенцы не могли бы выступать в роли покорителей этого края, и пережитые в прошлом страдания утратили бы свою значимость. Страдания, цивилизованная жизнь потеряли бы смысл, если бы оказалось, что до их прихода здесь уже жили люди, что враждебная тайга для других была домом. Именно поэтому память «коренного» населения должна быть отдалена от места страданий: в пространстве она ментально перемещается на территорию Югры, а во времени отодвигается в эпоху бронзы.

Данный анализ базируется преимущественно на материале, собранном мной во время полевых исследований 1990-х и 2000-х гг., но в период последних полевых исследований стали заметны и другие процессы. Прежде всего на территории района и Нового Васюгана наблюдается то, что активисты, формирующие память о выселениях и репрессиях, обратили внимание на «остяков». Точнее, в этой маргинальной социальнобытовой группе они обнаружили «хантов», т.е. ту этническую культуру. По этой причине в дальнейшем по отношению к ним я должен снова употреблять термин «ханты».

Во время последних полевых работ я заметил, что «остяки» иногда выступают в краеведческих мероприятиях нововасюганской школы, посвященных преимущественно народным мастерам и промыслам. Из этого видно, что презентация «хантов» как живых носителей этнического творчества отвечает требованиям, стереотипам большинства общества. Этот процесс неотделим от деятельности «культурных брокеров» национальных меньшинств, направленной на создание традиций, пат- 
римонизацию и предлагающей «хантыйскую» культуру для общественного потребления.

Истории «хантыйских» семей появляются также в изданиях и конференциях, имеют своей целью сохранение памяти района. По-видимому, все-таки возможно создание нарратива, включающего «хантов» в память региона, несмотря на то что их прежняя изолированность не менее мотивирована. Включение «хантов» в локальную память и в данном случае базируется на основном моменте истории региона: на памяти о репрессиях. Все чаще говорят о том, что без опыта и помощи «хантов» переселенцы едва ли смогли бы выжить. «Ханты», пусть косвенно, но тоже стали жертвами репрессий, их прежняя жизнь также была полностью перечеркнута этими двумя роковыми десятилетиями XX в.: их деревни были разрушены, а затем ликвидированы, они потеряли свои охотничьи угодья.

Таким образом, и тот и другой - действительно и одинаково трагический - индивидуальный опыт, физическое и моральное изгнание так называемых «спецов» из родных мест, и символическое вытеснение из родного края, выпавшее на судьбу остяков, не исклю- чают, а дополняют друг друга и равным образом могут стать частью господствующего нарратива травмы репрессий.

На примере васюганских хантов мы видим, как этническая группа может исчезнуть, а затем снова появиться в локальных дискурсах, т.е. как аборигенное население может затеряться между социально-бытовым и этническим дискурсами. На протяжении прошлого века васюганские ханты сперва маргинализировались, а затем из бытовой группы без какого-либо политического, культурного и хозяйственного веса превратились в этническую группу, обладающую весьма серьезным потенциалом.

Итак, процесс развивается в двух неразрывно связанных друг с другом направлениях - патримонизации и травматизации. Это обусловлено тем, что, с одной стороны, господствующий нарратив культурной травмы легко трансформируется и вбирает в себя новые нарративы, если этого требуют интересы агентов; с другой стороны, повышение престижа, вызванное включением новых нарративов, создает благоприятные условия для патримонизации, предоставления данной культуры для общественного потребления.

\title{
ПРИМЕЧАНИЯ
}

\author{
${ }^{1}$ URL:http://www.novvas.tomsk.ru/content/obshhie_svedenija \\ ${ }^{2}$ URL:http://www.novvas.tomsk.ru \\ ${ }^{3}$ Муниципальный историко-краеведческий музей г. Стрежевого. URL: http://www.museum.ru/M613
}

\section{ЛИТЕРАТУРА}

1. Nagy Z. “Miféle hantik vagyunk mi?” A vaszjugáni hantik és a világ // Közösség és identitás. Budapest : L’Harmattan - PTE Néprajz Tanszék, 2002. P. 33-77.

2. Всероссийская перепись населения 2010 года. Официальные итоги с расширенными перечнями по национальному составу населения и по регионам. URL: http:/www.gks.ru/free_doc/new_site/perepis2010/croc/results2.html, свободный.

3. Борзецов В.Л. Переселенцы. Красноярск : Поликом, 2001. 168 с.

4. Дорофеев С. Семейная история. Б.г. 190 с.

5. Шаповалов П.П. Ручей : сб. стихотворений. Томск : Знамя Мира, 1997. 178 с.

6. Надь 3. Лес: понятие ландшафта у хантов и русских Васюгана // Томский областной краеведческий музей. Материалы полевых исследований. Томск : Д-Принт, 2014. Т. XVIII. С. 243-249.

7. Решетко В. Черноводье. Томск : Красное знамя, 2007. 405 с.

8. Шелудяков А. Из племени кедра. Новосибирск : Зап.-Сиб. кн. изд-во, 1981. 320 с.

9. Шулбаева П.А. (сост.) Аборигенный экотуризм. Томская область. Путеводитель. М. : Россия, 2009.106 с.

10. Красильников С. Серп и Молох. Крестьянская ссылка в Западной Сибири в 1930-е годы. М. : РОССПЕН, 2003.288 с.

11. Макшеев В. Спецы. Исследование. Томск : СК-Сериц, 2007. 180 с.

12. Монголина Н.Г. Историческая справка о репрессиях 30-40-х гг. ХХ века. Очерк по истории сталинских репрессий // Гуманитарная экспедиция «Прошение и память 2006-2007 гг.» : сб. ст. Томск : Красное знамя, 2008. С. 8-14.

13. Alexander J.C. Toward a theory of Cultural Trauma // Cultural Trauma and Collective Identity. Berkeley: University of California Press, 2004.326 p.

Nagy Zoltán. University of Pécs (Pécs, Hungary). E-mail: nagyzooli@gmail.com

\section{VASYUGAN ON THE BORDER OF CENTURIES: KHANTIES OR OSTYAKS?}

Keywords: khanty; cultural trauma; patrimonization; cultural memory.

The topic of my presentation covers the public discourses about the Vasyugan Khanties living in the territory of the Tomsk Oblast'. The Khanties are not visible in the public sphere of the oblast'. The official and popular memory - which must not be mixed up with the forums of the historical sciences - only mentions archeological cultures as precedents to "real" Russian history. Why are the indigenous people, the Khanties so hidden? There are at least two possible answers. First, there is a lack of exoticism as another cause for their invisibility: the prototype of "Siberianism", of "aboriginality" was and is embodied for the majority in both high literature and popular culture by the Khanties of the KhMAO and the Evenki. Thirdly in the memory of the okrug the key role is played by the deportations, the modern self-image of the region is being developed along repression process. In the "master narrative" of the deportations natives have no place: they would apparently lose the sense or significance of their suffering, if they acknowledged that before them the place had already been civilized, humanized. The concept of Khanties in local public discourse makes it hard for the Khanties to acknowledge their Khanty identity and to integrate the Khanty memories into a common collective remembrance. The population of the oblast' conceive of the Khanties as a special social group distinguished by their way of life, and not as an ethnic group. This conception has elements of neutral value such as the view on their close attachment to the forest and the taiga. The negative connotations associated with the "Khanty" as a life-style community are stronger, envisaging them as members of a poverty culture, in most cases a marginalized, 
lumpenized culture. The Vasyugan Khanties epitomize how an ethnic group can become invisible, then visible again in the local discourse; how natives can be lost tossed between life-style and ethnic discourses. From a marginalized life-style group without political, cultural and economic potential the Vasyugan Khanties have become an ethnic group of considerable potential upon the deliberate or unintentional, direct or indirect influence of the scholarly sphere and some individual researchers. The process is going on along two inseparable lines, patrimonization and traumatization.

\section{REFERENCES}

1. Nagy, Z. (2002) “Miféle hantik vagyunk mi?” A vaszjugáni hantik és a világ [Khanty and the Vasyugan world]. In: Pócs, É. (ed.) Közösség és identitás [Community and identity]. Budapest: L'Harmattan - PTE Néprajz Tanszék. pp. 33-77.

2. The Russian State Statistics Committee. (2010) Vserossiyskaya perepis' naseleniya 2010 goda. Ofitsial'nye itogi s rasshirennymi perechnyami po natsional'nomu sostavu naseleniya i po regionam [National Population Census 2010. Official results from the extended sets by the ethnic composition of the population and by regions]. [Online] Available from: http://www.gks.ru/free_doc/new_site/perepis2010/croc/results2.html.

3. Borzetsov, V.L. (2001) Pereselentsy [Migrants]. Krasnoyarsk: Polikom.

4. Dorofeev, S. (s.a.) Semeynaya istoriya [Family history]. [s.n.].

5. Shapovalov, P.P. (1997) Ruchey. Sbornik stikhotvoreniy [The Creek. A Collection of Poems]. Tomsk: Znamya Mira.

6. Nad, Z. (2014) Les: ponyatie landshafta u khantov i russkikh Vasyugana [The forest: The concept of landscape in Khanty and Russian Vasyugan]. In: Tomskiy oblastnoy kraevedcheskiy muzey. Materialy polevykh issledovaniy [Tomsk Regional Museum of Local Lore. Materials of fieldwork]. Vol. 18. Tomsk D-Print. pp. 243-249.

7. Reshetko, V. (2007) Chernovod'e [Blackwaters]. Tomsk: Krasnoe znamya.

8. Sheludyakov, A. (1981) Iz plemeni kedra [From the cedar tribe]. Novosibirsk: West Siberian Book Publ.

9. Shulbaeva, P.A. (2009) Aborigennyy ekoturizm. Tomskaya Oblast', Putevoditel' [The aboriginal ecotourism. The Tomsk Region Guide]. Moscow: Rossiya.

10. Krasilnikov, S. (2003) Serp i Molokh. Krest'yanskaya Ssylka v Zapadnoy Sibiri v 1930-e gody [The Sickle and Moloch. The peasant exile in Western Siberia in the 1930s]. Moscow: ROSSPEN.

11. Maksheev, V. (2007) Spetsy. Issledovanie [Specialists. A Reasearch]. Tomsk: SK-Serits.

12. Mongolina, N.G. (2008) Istoricheskaya spravka o repressiyakh 30-40-kh gg. XX veka. Ocherk po istorii stalinskikh repressiy[Historical information about the repressions of the 1930-1940s. An essay on the history of Stalinist repressions]. In: Zarubina, V.M. (ed.) Gumanitarnaya ekspeditsiya. Proshenie i pamyat' 2006-2007 gg. [The Humanitarian Expedition "Remission and Memory 2006-2007"]. Tomsk: Krasnoe znamya. pp. 8-14.

13. Alexander, J.C. (2004) Toward a theory of Cultural Trauma. In: Alexander, J.C., Eyerman, R., Giesen, B., Smelser, N. \& Sztompka, P. Cultural Trauma and Collective Identity. Berkeley: University of California Press. 